\title{
The effect of temperature on fatigue crack growth in FM94 epoxy adhesive bonds investigated by means of energy dissipation
}

\author{
M. Usman ${ }^{\text {a }}$,J.A. Pascoe ${ }^{\mathrm{a}, *}$, R.C. Alderliesten ${ }^{\text {a }}$, R. Benedictus ${ }^{\mathrm{a}}$ \\ ${ }^{a}$ Structural Integrity \& Composites group, Faculty of Aerospace Engineering, Delft University of Technology. P.O. Box 5058, \\ 2600 GB Delft, The Netherlands
}

\begin{abstract}
The effect of temperature on fatigue crack growth in epoxy adhesive bonds was investigated for a range of temperatures from -55 to $80^{\circ} \mathrm{C}$. The fatigue crack growth behaviour was characterised using both strain energy release rate (SERR) and by measurements of energy dissipation. It was found that for a given maximum SERR, or a given energy dissipation per cycle, crack growth rate was higher at higher temperatures.

The resistance to crack growth (in terms of energy dissipation per unit crack growth) was linearly related to the maximum SERR, and this relationship was not affected by temperature. A number of tests did show anomalous behaviour, which could be linked to differences on the fracture surfaces. Previous work had found a power-law relationship between the amount of available energy and the applied cyclic work. This relationship was found to be insensitive to temperature changes in the range of $0{ }^{\circ} \mathrm{C}$ to $40{ }^{\circ} \mathrm{C}$, but at $-55{ }^{\circ} \mathrm{C}$ and $-20^{\circ} \mathrm{C}$, as well as at $60{ }^{\circ} \mathrm{C}$ and $80{ }^{\circ} \mathrm{C}$, the behaviour was affected by temperature. This could again be linked to differences on the fracture surfaces.

It was concluded that temperature does not affect crack growth by directly affecting the failure mechanisms themselves, but rather by affecting which mechanisms are active.
\end{abstract}

Keywords: Adhesive Bonds, Energy Dissipation, Fatigue Crack Growth, Temperature

\section{Note}

This is the accepted author manuscript version of a paper published in Engineering Fracture Mechanics, which may be found at: https://doi.org/10.1016/j.engfracmech.2017.10.007,

The full citation of the version of record is: M. Usman, J.A. Pascoe, R.C. Alderliesten, R. Benedictus 5 (2018), The effect of temperature on fatigue crack growth in FM94 epoxy adhesive bonds investigated by means of energy dissipation, Engineering Fracture Mechanics, 189, pp 98-109.

(C)2018. This manuscript version is made available under the CC-BY-NC-ND 4.0 license http:// creativecommons.org/licenses/by-nc-nd/4.0/.

\section{Introduction}

In service, an aircraft faces a wide range of temperatures. At cruise altitude, the air temperature typically drops to around $-55^{\circ} \mathrm{C}$. Sitting on the tarmac near the equator on the other hand, the aircraft's skin temperature may reach $80{ }^{\circ} \mathrm{C}$. Consequently, a full understanding of the effect of temperature on the fatigue properties of aerospace materials is required in order to ensure the safety of aircraft structures.

Compared to the mechanical joining techniques traditionally used in aircraft structures, adhesive bonding offers the promise of significant weight savings. By avoiding the need for stress concentrators like holes and

\footnotetext{
${ }^{*}$ Corresponding author

Email address: j.a.pascoe@tudelft.nl; johnalan.pascoe@gmail.com (J.A. Pascoe )
} 


\begin{tabular}{|c|c|c|c|}
\hline \multicolumn{4}{|c|}{ Nomenclature } \\
\hline$A$ & Curve fit parameter $(\mathrm{N} / \mathrm{mm})$ & $R$ & Ideal gas constant $(\mathrm{J} / \mathrm{mol} \mathrm{K})$ \\
\hline$a$ & Crack length $(\mathrm{mm})$ & $R$ & Load ratio \\
\hline$b_{0}$ & $\begin{array}{l}\text { Material constant in the Charalambous } \\
\text { model }\end{array}$ & $T$ & Temperature $\left({ }^{\circ} \mathrm{C}, \mathrm{K}\right)$ \\
\hline$C$ & Curve fit parameter & $t$ & Time (s) \\
\hline$d$ & Displacement $(\mathrm{mm})$ & $T_{0}$ & Reference temperature $(\mathrm{K})$ \\
\hline$d_{0}$ & Diesplacement for zero force (mm) & $U$ & Strain energy $(\mathrm{m} J)$ \\
\hline$E$ & Young's modulus (MPa) & $w$ & Width $(\mathrm{mm})$ \\
\hline$G$ & $\begin{array}{l}\text { Strain energy release rate }\left(\mathrm{mJ} / \mathrm{mm}^{2} \text {, }\right. \\
\mathrm{N} / \mathrm{mm})\end{array}$ & $\gamma$ & $\begin{array}{l}\text { Material constant in the Charalambous } \\
\text { model }\end{array}$ \\
\hline$\Delta G$ & $\begin{array}{l}\text { Strain energy release rate range } \\
\left(\mathrm{mJ} / \mathrm{mm}^{2}, \mathrm{~N} / \mathrm{mm}\right)\end{array}$ & $\begin{array}{l}\nu \\
\text { Subs }\end{array}$ & $\begin{array}{l}\text { Poisson's ratio } \\
\text { ripts }\end{array}$ \\
\hline$G^{*}$ & $\begin{array}{l}\text { Energy dissipation per unit crack growth } \\
\left(\mathrm{mJ} / \mathrm{mm}^{2}\right)\end{array}$ & c & Critical \\
\hline$K$ & Stress intensity factor $(\mathrm{MPa} \sqrt{\mathrm{mm}})$ & & Cyclic \\
\hline$\Delta K$ & Stress intensity factor range $(\mathrm{MPa} \sqrt{\mathrm{mm}})$ & 1 & Mode 1 \\
\hline$N$ & Cycle number & $\min$ & Minimum \\
\hline$n$ & Compliance calibration parameter & $\max$ & Maximum \\
\hline$n$ & Curve fit parameter & mon & Monotonic \\
\hline$P$ & Force $(\mathrm{N})$ & th & Threshold \\
\hline$Q$ & Activation energy $(\mathrm{J})$ & tot & Total \\
\hline
\end{tabular}

point loads, adhesive bonding allows for lower weight joint designs. However, the wide-scale application of adhesive bonding for safety-critical structures is still limited by a lack of knowledge of fatigue crack growth behaviour in adhesives, as well as a lack of adequate non destructive inspection (NDI) techniques.

Although a variety of prediction models has been proposed for fatigue crack growth (FCG) in adhesives, these are invariably based on empirical curve fits, rather than an underlying physical theory [1]. Consequently the range of validity of these models is limited. Furthermore, few researchers have investigated the effect of temperature on FCG in adhesives [2-6].

The goal of the present research was therefore to increase the understanding of the effect of temperature on FCG, in terms of its affect on both the resistance to crack growth, and the energy available for crack growth in a given cycle. To do this the energy dissipation approach [7-9] was used to characterise FCG over a range of temperatures relevant to aviation applications. Before discussing the test set-up and the results, a brief literature review will be given.

\section{Literature Review}

As mentioned above, only a small number of studies has been published on the effect of temperature on FCG rate in adhesives. Therefore this literature review will also cover work that has been done on fatigue delamination growth in fibre-reinforced polymers (FRP), as this generally involves growth of a crack through a thin resin rich layer. This can be interpreted as crack growth through an 'adhesive' layer joining two laminae. 
Investigations on FCG in adhesive bonds have been reported by Russell [2, Ashcroft et al. 3, 4, Datla 35 et al. [5] and Pascoe [6]. The effect of temperature on FCG in epoxies has been investigated in FRPs by Chan and Wang [10, Sjögren and Asp [11, Shindo et al. [12-14, Coronado et al. [15], and Charalambous et al. [16. In fibre metal laminates (FMLs) the temperature effect has been studied by Burianek and Spearing 17 and Rans et al. 18 .

The general trend that is reported in these investigations is that an increase in temperature results in an increase in the crack growth rate [2-6, 10, 17. However, several researchers have also reported nonmonotonous behaviour at upper and lower ends of the tested temperature range [15, 18] or at cryogenic temperatures [12-14]. The monotonous temperature effect trends will be discussed first:

Russell [2] performed mode II tests on three different epoxy adhesives (FM-300K, FM-300, and EA-9321) at three different temperatures $\left(-50{ }^{\circ} \mathrm{C}, 20^{\circ} \mathrm{C}\right.$, and $\left.100{ }^{\circ} \mathrm{C}\right)$. Russell reported an increase of the FCG rate for an increase of the temperature.

Ashcroft et al. [3, 4] tested a "proprietary modified epoxy", at $-50,22$, and $90{ }^{\circ} \mathrm{C}$. They also found that at higher temperatures the crack growth rate increased. The same was found by Pascoe in his investigation of FCG in FM73 [6] and by Datla et al. [5] for FCG in an unspecified "single-part, heat-cured toughened epoxy adhesive".

Chan and Wang [10] found a reduction of the fracture toughness of an epoxy GFRP at lower temperatures, but an increase of the exponent of a power-law correlation between crack growth rate and maximum strain energy release rate (SERR), $G_{\max }$. In other words, the material became more brittle, and more sensitive to the applied load, at lower temperatures. An increased crack growth rate and reduced fatigue threshold for higher temperatures was reported by Sjögren and Asp [11.

Non-monotonous behaviour was reported by Coronado et al. [15], Shindo et al. [12-14] and Rans et al. [18]. Coronado et al. investigated delamination growth in a carbon-fibre reinforced epoxy. They found an increase of the crack growth rate for an increase of temperature, when the temperature was in the range of $-30{ }^{\circ} \mathrm{C}$ to $50{ }^{\circ} \mathrm{C}$. However, this trend reversed at both higher and lower temperatures, i.e. the crack growth at $90{ }^{\circ} \mathrm{C}$ was slower than at $50{ }^{\circ} \mathrm{C}$ and at $-60{ }^{\circ} \mathrm{C}$ it was faster than at $-30{ }^{\circ} \mathrm{C}$. Coronado et al. suggested that this change in behaviour was caused by the temperature dependence of the matrix toughness.

Shindo et al. 12 14 compared FCG in glass-fibre reinforced polymers (GFRP) at cryogenic temperatures with FCG at room temperature. They found that at both $77 \mathrm{~K}$ and $4 \mathrm{~K}$ the crack growth rate was lower than at room temperature, but that it was higher at $4 \mathrm{~K}$ than at $77 \mathrm{~K}$. They suggested this was caused by freezing of the molecular motion of the matrix at $4 \mathrm{~K}$, preventing stress relaxation.

Rans et al. [18 investigated delamination growth in an FML. They found that delamination growth was faster at both $-20{ }^{\circ} \mathrm{C}$ and $70{ }^{\circ} \mathrm{C}$ than at room temperature. At $70{ }^{\circ} \mathrm{C}$ the crack growth rate was faster than at $-20{ }^{\circ} \mathrm{C}$. No hypothesis was proposed to explain this behaviour.

The investigations listed above all only produced qualitative statements on the effect of temperature. Quantitative relationships between temperature and crack growth rate have been proposed by Burianek and Spearing [17] and Charalambous et al. [16].

Burianek and Spearing combined the standard Paris-relationship with an Arrehenius relation to produce the model:

$$
\frac{\mathrm{d} a}{\mathrm{~d} N}=C e^{\left(\frac{-Q}{R T}\right)}(\Delta G)^{n}
$$

where $\mathrm{d} a / \mathrm{d} N$ is the crack growth rate, $Q$ is the activation energy, $R$ is the ideal gas constant, $\Delta G$ is the SERR range, and $T$ is the temperature.

Charalambous et al. [16] suggested a different modification of the Paris-relationship, viz:

$$
\frac{\mathrm{d} a}{\mathrm{~d} N}=C\left(\frac{G_{\max }}{G_{c}}\right)^{b(T)}
$$

where $G_{\max }$ is the maximum SERR, $G_{c}$ is the critical $G$ for quasi-static loading, and the exponent is now a function of the temperature, according to:

$$
b(T)=b_{0}\left(\frac{T}{T_{0}}\right)^{\gamma}
$$


where $b_{0}$ and $\gamma$ are material constants and $T_{0}$ is a reference temperature.

Both Burianek and Spearing, and Charalambous et al., found a good correlation between their respective proposed models and their test data. This makes their models usable for predictions. However, because both models are mainly based on empirical curve fits, rather than on an underlying physical theory of FCG, they provide little insight into the physics of the temperature effect. Furthermore, it is unclear how to account for effects of the $R$-ratio or mode-mixity within these models.

In the present research the energy dissipation approach suggested by Pascoe et al. [7-9 is used to characterise the effect of temperature on fatigue crack growth. In this approach the measured forces and displacements are used to calculate the strain energy $U_{t o t}$ in the system, defined as [7]:

$$
U_{\text {tot }}=\frac{1}{2} P_{\max }\left(d_{\max }-d_{0}\right) .
$$

where $P$ is the force on the specimen, $d$ is the displacement, $d_{0}$ is the displacement for zero force, and linear elastic behaviour of the specimen is assumed. By measuring $U_{\text {tot }}$ at regular intervals during the experiment, the energy dissipation $\mathrm{d} U / \mathrm{d} N$ can be determined. The energy dissipation in a certain fatigue cycle can then be compared to the crack growth rate, and the applied load in that same cycle, in order to characterise the crack growth behaviour.

An important feature of the energy dissipation approach is that it makes it possible to separately characterise the resistance to crack growth, and the energy available for crack growth [7, 9].

The resistance to crack growth is related to $G^{*}$, defined as [7, 8]:

$$
G^{*}=\frac{1}{w} \frac{\mathrm{d} U / \mathrm{d} N}{\mathrm{~d} a / \mathrm{d} N}
$$

where $w$ is the specimen width. $G^{*}$ represents the amount of energy dissipation required per unit of crack growth, and can therefore be interpreted as a measure for the resistance to crack growth. Previously it has been found that $G^{*}$ shows a strong linear correlation with the maximum load $\left(G_{\max }\right)$ [7-9].

On the other hand $\mathrm{d} U / \mathrm{d} N$ represents the amount of energy dissipated during a single cycle, and therefore is a measure for the amount of energy available for crack growth. Previously $\mathrm{d} U / \mathrm{d} N$ was shown to be related to the load range (in terms of either $\Delta G$, or the work applied during the loading portion of the cycle, $U_{c y c}$ ) [7, 9].

In 17, 9, the authors therefore argued that the amount of crack growth in a single cycle depends on both the maximum load (which relates to the resistance to crack growth), and the load range (which relates to the amount of energy available for crack growth).

This paper shows the effect of temperature on these relationships. In other words, it investigates if and how temperature affects the crack growth resistance for a given maximum load, and if and how temperature affects the relationship between the available energy and the load range. These results shed new light on how temperature affects fatigue crack growth and provide a focus for future investigations of the (micro)mechanics of crack growth.

\section{Experimental methodology}

Fatigue tests were conducted on double cantilever beam specimens (DCB), based on the design given in ASTM standard D5528-01 [19. The specimens consisted of two arms of Al-2024-T3, with a nominal thickness of $6 \mathrm{~mm}$ per arm. The arms were joined with Cytec FM94K.03AD FILM 915; an epoxy film adhesive. To manufacture the specimens, first two aluminium plates were bonded together. Prior to bonding, the plates had been pre-treated using chromic acid anoidisation (CAA) and BR-127 primer. After pre-treatment the plates were stored under uncontrolled room temperature conditions for several months. Before curing a teflon tape was applied over a portion of the plates in order to create a pre-crack. The adhesive was cured in an autoclave using the standard cure cycle for FM94; 1 hour at $120{ }^{\circ} \mathrm{C}$ and $0.6 \mathrm{MPa}(6$ bar) pressure. After curing the plates were cut into strips and then milled to the final dimensions. The nominal specimen dimensions were a length of $145 \mathrm{~mm}$ and a width of $25 \mathrm{~mm}$. Post curing the adhesive thickness was found 
to be $0.09 \mathrm{~mm}$ [20]. The side of the specimens was coated with diluted white type-writer correction fluid in order to make the crack more visible.

Fatigue tests were performed on an MTS $10 \mathrm{kN}$ servo-hydraulic fatigue machine, under displacement control, and at a frequency of $5 \mathrm{~Hz}$. Prior to each fatigue test, the specimen was loaded quasi-statically in order to generate a pre-crack.

A climate chamber was placed around the specimen in order to ensure the desired temperature. The temperature inside the climate chamber was controlled using using a thermocouple exposed to the air inside the climate chamber and placed near to the specimen. After setting the desired temperature, a wait time of at least 1 hour was maintained, in order to allow the system to achieve thermal equilibrium.

To verify the time required to reach thermal equilibrium, one specimen was manufactured with a thermocouple embedded in the bond-line and placed in the climate chamber at $-20^{\circ} \mathrm{C}$. After 1 hour the temperature at the bond-line remained constant.

The presence of the thermocouple distorts the bond-line and might therefore influence the crack growth rate. Therefore, during the actual FCG tests, the temperature of the climate chamber was controlled with a thermocouple placed in the free air near the specimen.

Force and displacement were measured by the testing machine; the maximum and minimum values were recorded every 100 cycles. At the last calibration, the error in the force measurement was measured as $0.64 \%$ of the calibration value at $100 \mathrm{~N}$ of applied force. The error in the displacement measurement was determined to be $0.02 \%$ of the calibration value at $5 \mathrm{~mm}$ displacement.

Especially for the displacement measurement, it is possible that the temperature changes affected the magnitude of the error. However, it should be noted that each individual test was conducted at a constant temperature, and that the displacement measurement was zeroed at the start of each test. Furthermore, the energy values were all calculated based on relative displacements, negating the effect of thermal expansion. Thus the effect of the temperature on the measurement accuracy is though to be negligible.

The crack length was recorded with a camera aimed at the side of the specimen. The camera was placed outside the climate chamber, and viewed the specimen through a window. Although the window did affect the image quality somewhat, it was still possible to determine the crack length sufficiently accurately. The image resolution was on the order of 20 pixels per $\mathrm{mm}$, with slight variations depending on the exact positioning of the camera for each test. Photographs were taken once every 100 cycles at the start of the test. As the test progressed and the crack growth rate decreased, the interval between photographs was increased.

The crack growth rate was determined by fitting a power-law curve through the $a$ vs $N$ data and taking the derivative. The energy dissipation was determined by taking a the derivative of a power-law fit through the $U$ vs $N$ data, where $U$ was determined from the recorded force and displacement data, as explained above, and in reference [7.

Strain energy release rate values were calculated using the compliance calibration method given in ASTM standard D5528-01 [19, i.e:

$$
G=\frac{n P d}{2 w a}
$$

where $n$ is a calibration parameter which is equal to the slope of a linear fit of the $\log C$ vs $\log a$ data. $C$ is the specimen compliance, calculated as:

$$
C=\frac{d_{\max }-d_{\min }}{P_{\max }-P_{\min }}
$$

Table 1 shows the experiments performed during this research. The raw and processed data from these experiments is publicly available to be downloaded [21].

\section{Results and discussion}

Figure 1 shows the results of the fatigue tests, using the traditional method of plotting $\mathrm{d} a / \mathrm{d} N$ against $G_{\max }$. For clarity the figure shows both the total data set, as well as the data grouped per $R$-ratio tested. 
Table 1: Test matrix for the experiments conducted during this research. The data for these experiments is available from 21]

\begin{tabular}{lcc}
\hline Experiment number & Temperature & $R$-ratio \\
\hline-55 R0.036 & $-55{ }^{\circ} \mathrm{C}$ & 0.036 \\
-55 R0.29 & $-55{ }^{\circ} \mathrm{C}$ & 0.29 \\
-55 R0.61 & $-55{ }^{\circ} \mathrm{C}$ & 0.61 \\
-55 R0.61R & $-55{ }^{\circ} \mathrm{C}$ & 0.61 \\
-20 R 0.036 & $-20{ }^{\circ} \mathrm{C}$ & 0.036 \\
-20 R0.036R & $-20{ }^{\circ} \mathrm{C}$ & 0.036 \\
-20 R0.29 & $-20{ }^{\circ} \mathrm{C}$ & 0.29 \\
-20 R0.61 & $-20{ }^{\circ} \mathrm{C}$ & 0.61 \\
-20 R0.61R & $-20{ }^{\circ} \mathrm{C}$ & 0.61 \\
Zero Deg R0.036 & $0{ }^{\circ} \mathrm{C}$ & 0.036 \\
Zero Deg R0.29 & $0{ }^{\circ} \mathrm{C}$ & 0.29 \\
Zero Deg R0.61 & $0{ }^{\circ} \mathrm{C}$ & 0.61 \\
RT R0.036 & Room temperature & 0.036 \\
RT R0.29 & Room temperature & 0.29 \\
RT R0.61 & Room temperature & 0.61 \\
40 R0.036 & $40{ }^{\circ} \mathrm{C}$ & 0.036 \\
40 R0.29 & $40{ }^{\circ} \mathrm{C}$ & 0.29 \\
40 R0.61 & $40{ }^{\circ} \mathrm{C}$ & 0.61 \\
60 R0.036 & $60{ }^{\circ} \mathrm{C}$ & 0.036 \\
60 R0.036R & $60{ }^{\circ} \mathrm{C}$ & 0.036 \\
60 R0.29 & $60{ }^{\circ} \mathrm{C}$ & 0.029 \\
60 R0.61 & $60{ }^{\circ} \mathrm{C}$ & 0.61 \\
80 R0.036 & $80{ }^{\circ} \mathrm{C}$ & 0.036 \\
80 R0.29 & $80{ }^{\circ} \mathrm{C}$ & 0.29 \\
80 R0.61 & $80{ }^{\circ} \mathrm{C}$ & 0.61 \\
\hline
\end{tabular}

There is a clear effect of both $R$-ratio and temperature. For a given temperature and $G_{\max }$, increasing $R$ causes a reduction of the crack growth rate. This is expected, as keeping $G_{\max }$ constant and increasing $R$ implies reducing $\Delta G$, and the crack growth rate is a function of both the maximum load and the load range [7, 9. For a given combination of $G_{\max }$ and $R$, an increase of the temperature results in an increased crack growth rate, matching what has been reported in literature.

To gain more insight into the physical mechanisms behind this increase in crack growth rate, the energy dissipation during the fatigue tests was examined. Figure 2 shows the crack growth rate as a function of the energy dissipation per cycle for all the experiments performed as part of this research.

To better see the effect of temperature, this data is shown grouped by $R$-ratio in figures 3 through 5 , These figures show both the entire data-subset, and a zoomed-in portion of the data. In general the trend is that for a fixed energy dissipation value, an increasing temperature results in a higher crack growth rate. In other words: at higher temperatures there is a greater amount of crack growth, for the same amount of dissipated energy.

Following the approach established in 7 the amount of energy required to generate a fixed amount of crack growth was examined for the different tests. This is shown in figure 6. For a given fixed crack growth rate, there is a strong linear correlation between the amount of energy dissipation and $G_{\max }$. This was also seen for the room temperature experiments described in [7].

Furthermore, one can see a trend that more energy is required to create $10^{-4} \mathrm{~mm} /$ cycle crack growth as the temperature reduces. This is matched by an increase of the corresponding $G_{\max }$ value. This corresponds to the trends identified in the previous figures, that at higher temperature less energy dissipation was required 


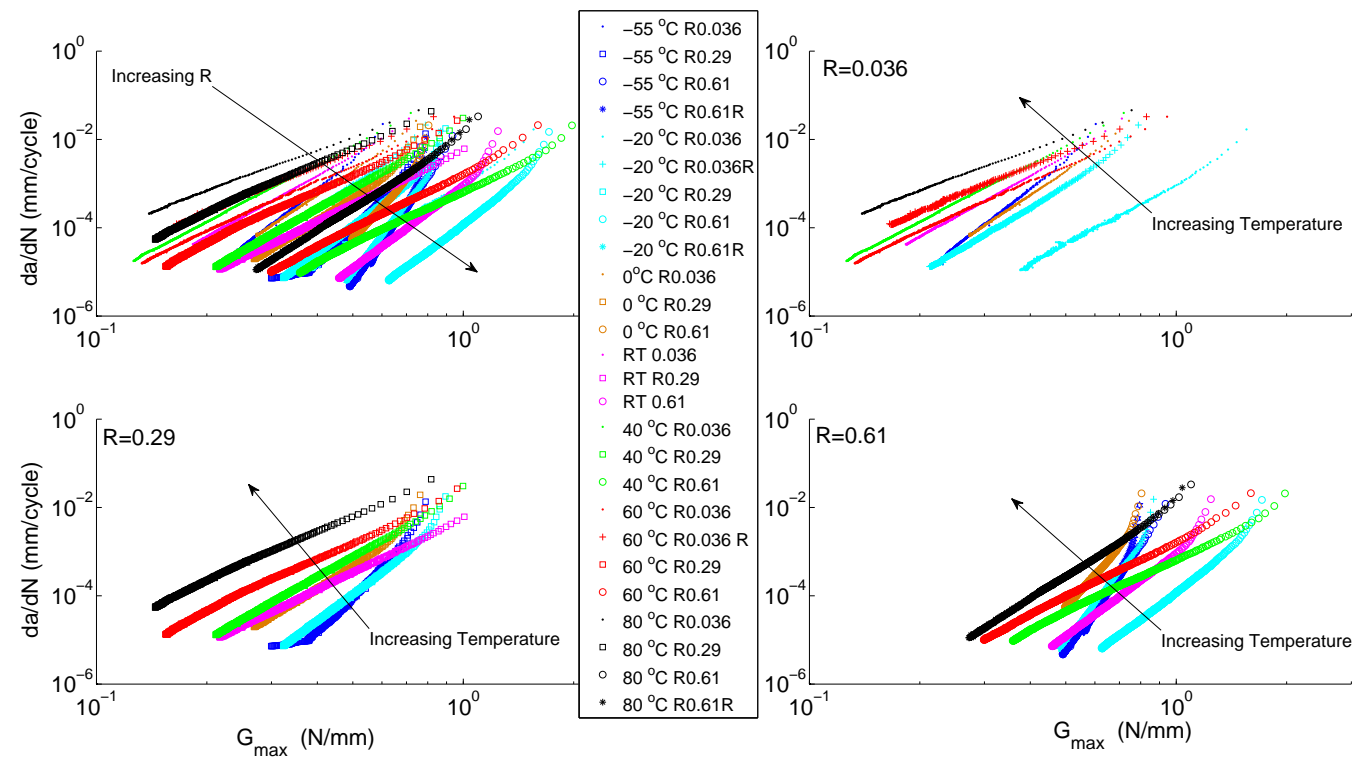

Figure 1: Crack growth rate as a function of $G_{\max }$. The top left panel shows the results for all experiments. The top right panel shows only the results for $R=0.036$, the bottom left shows $R=0.29$, and the bottom right panel shows $R=0.61$. Increasing $R$ (and keeping $G_{\max }$ constant) resulted in a decrease of the crack growth rate. Conversely, an increase in temperature produced an increased crack growth rate.

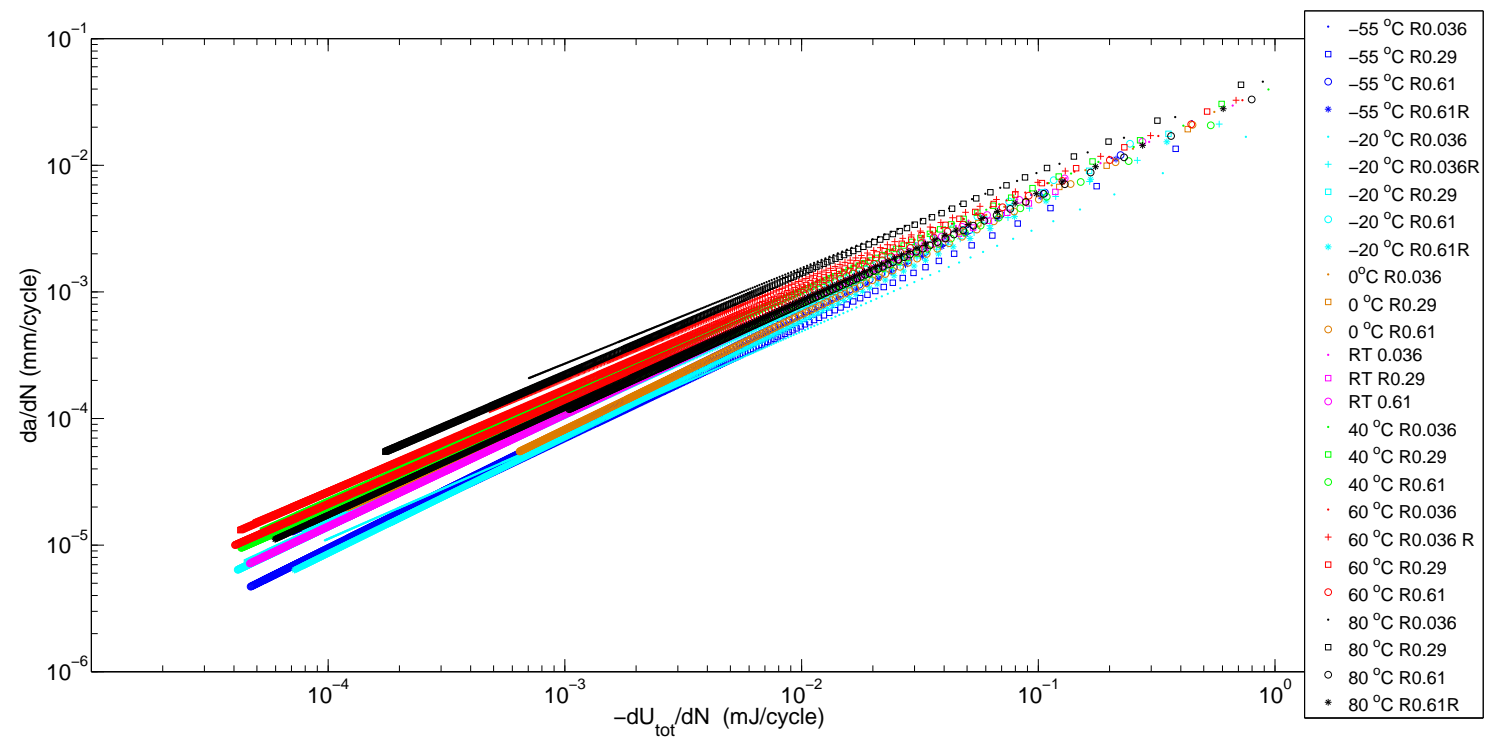

Figure 2: Crack growth rate as a function of energy dissipation per cycle $\mathrm{d} U / \mathrm{d} N$. Data is shown for all experiments combined.

for the same crack growth rate.

Nevertheless the $\mathrm{d} U / \mathrm{d} N$ vs $G_{\max }$ trend itself does not seem to be affected by the temperature. For a higher temperature, both the $G_{\max }$ and the $\mathrm{d} U / \mathrm{d} N$ needed to produce $10^{-} 4 \mathrm{~mm} /$ cycle of crack growth

reduce proportionally. In other words, while temperature does affect the resistance to crack growth, it does not affect the relationship between resistance and maximum load. 

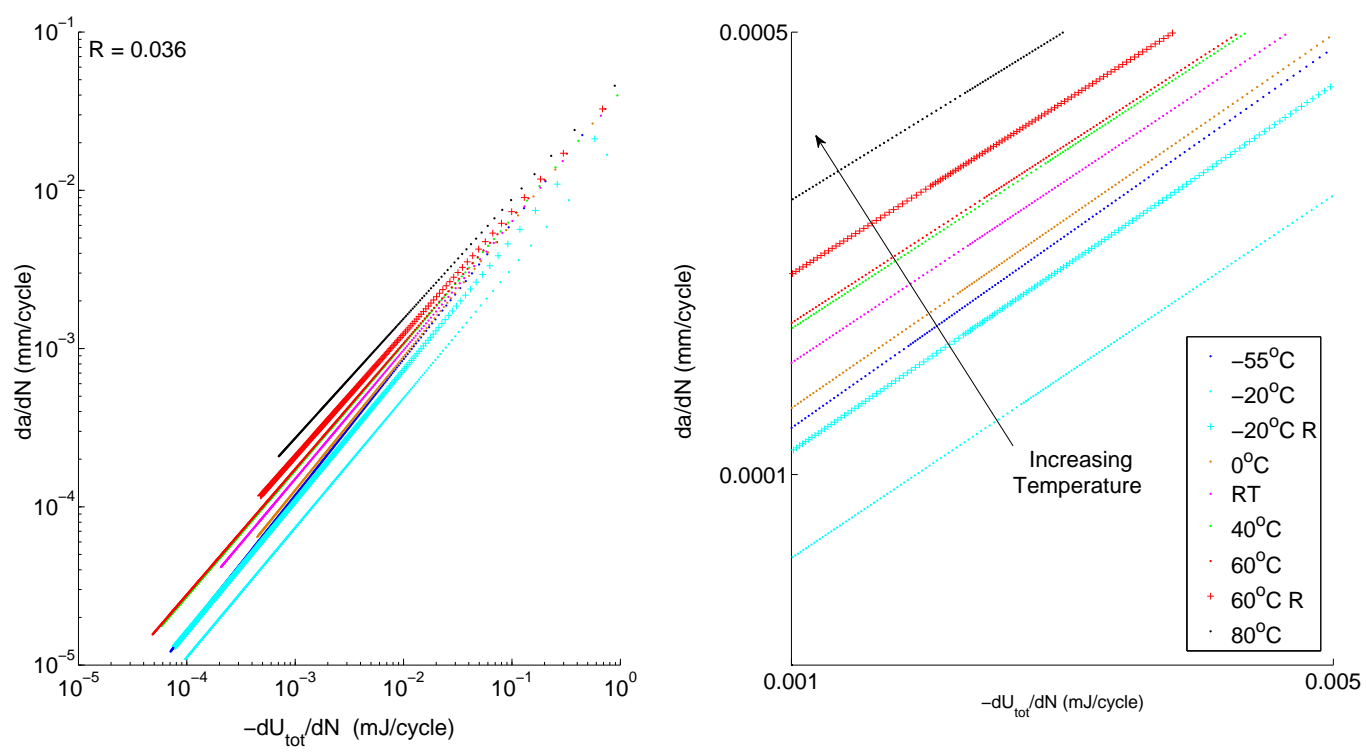

Figure 3: Crack growth rate as a function of energy dissipation per cycle $\mathrm{d} U / \mathrm{d} N$, for $R=0.036$. A zoomed-in view of a portion of the graph is shown in the right-hand panel.
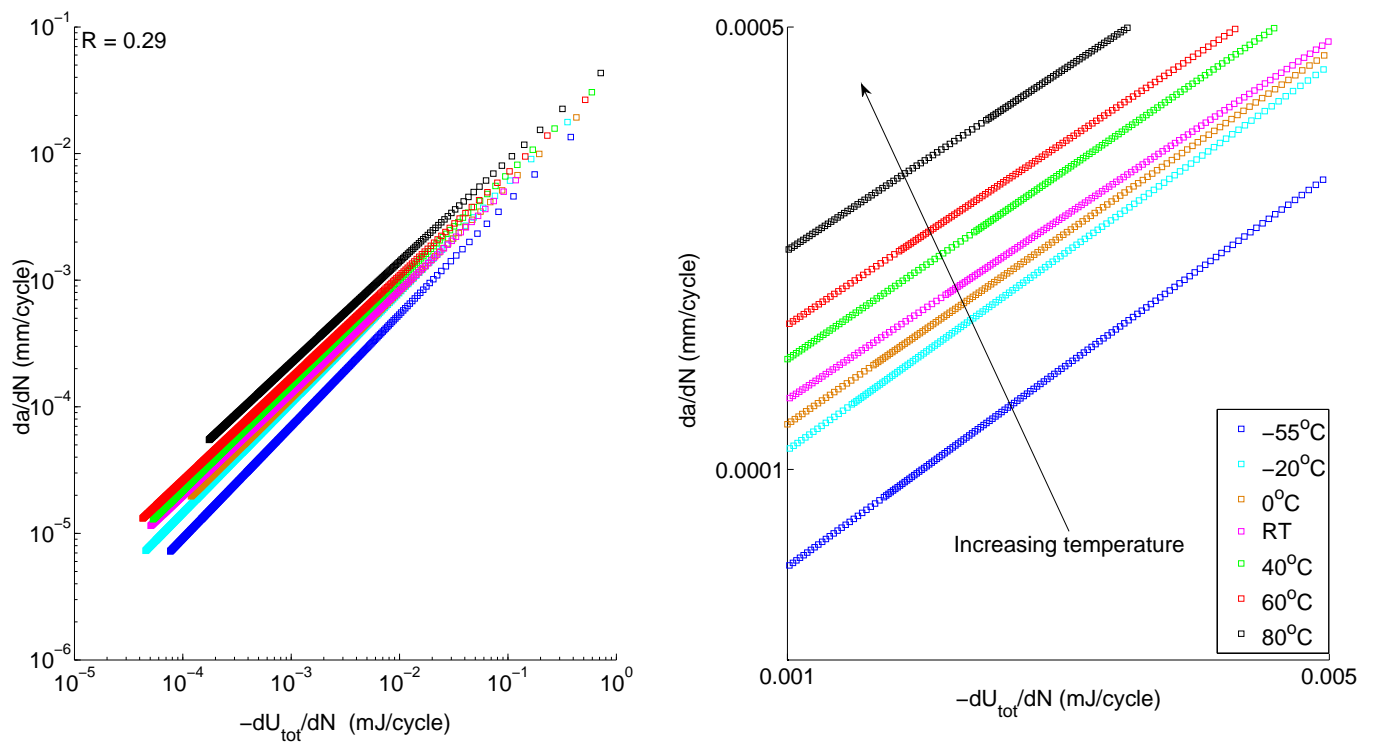

Figure 4: Crack growth rate as a function of energy dissipation per cycle $\mathrm{d} U / \mathrm{d} N$ for $R=0.29$. A zoomed-in view of a portion of the graph is shown in the right-hand panel.

Although most of the data in figure 6 lies close to the linear fit, four data-points appear to be outliers. All these points correspond to tests conducted at an $R$-ratio of 0.61 . One of these tests $\left(-20{ }^{\circ} \mathrm{C}\right.$ at $\left.R=0.61\right)$ was repeated. The data point corresponding to the repeated test matches the trend of the bulk of the data, as indicated in figure 6. This supports the treatment of the indicated points as outliers.

The four tests indicated as outliers here also show anomalous behaviour if one plots $G^{*}$ versus $G_{\max }$ for the entire test, as done in figure 7. Again most of the data is clustered together along a linear trend, albeit 

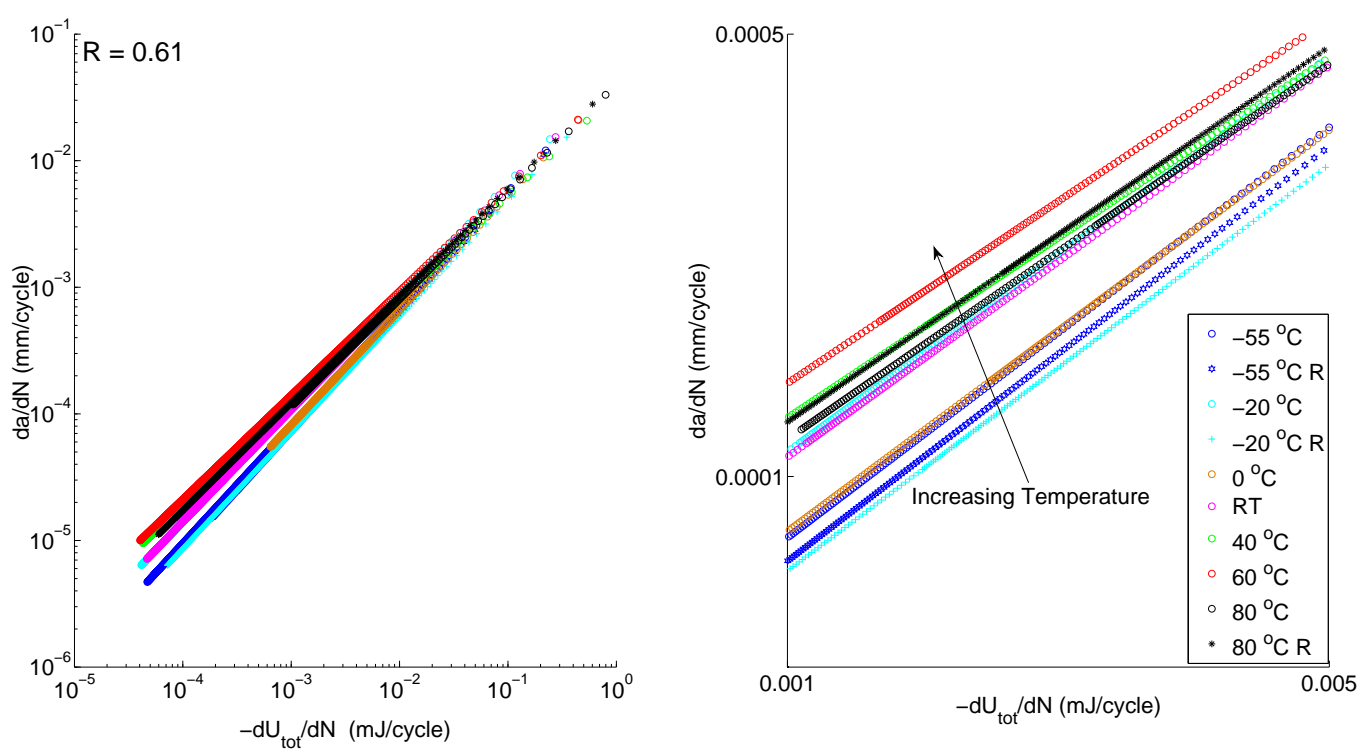

Figure 5: Crack growth rate as a function of energy dissipation per cycle $\mathrm{d} U / \mathrm{d} N$ for $R=0.61$. A zoomed-in view of a portion of the graph is shown in the right-hand panel.

with some spread in the slope of the lines. However, the difference in slope does not seem to systematically depend on the temperature, and therefore may be related to material or specimen variation. The $R=0.61$ tests at room temperature, $40{ }^{\circ} \mathrm{C}, 60{ }^{\circ} \mathrm{C}$, and one of the $R=0.036$ tests performed at $-20{ }^{\circ} \mathrm{C}$, form a distinct grouping with a different slope compared to the bulk of the data. These are the same tests previously marked as outliers in figure 6 .

The exact cause of this difference in behaviour is unclear, but some clues may be offered by the fractographic examination that was conducted. Magnified images of the fracture surfaces are shown for four different tests in figures 8 and 9 .

Each figure shows one test that behaved according to the bulk of the test data (on the left), and one test that was an outlier (on the right). The fracture surfaces of the typical tests and those of the outliers are not the same. For the $-20{ }^{\circ} \mathrm{C}$ tests (figure 8), the fatigue fracture surface for the first test (outlier) is much flatter and smoother than for the repeat test (typical behaviour).

For the $40^{\circ} \mathrm{C}$ tests, the $R=0.61$ test (outlier) shows adhesive residue on both fracture surfaces, indicating a cohesive failure mode in the bulk of the adhesive. In contrast, for $R=0.29$ large portions of one of the surfaces seem to be almost free of adhesive residue, indicating the failure was either adhesive, or cohesive but occurring close to one of the adhesive / adherent interfaces.

The exact differences in crack growth mechanisms that cause these different fracture surfaces need to be investigated further.

Given the limited number of tests at the same conditions performed during this project, one needs to be careful about labelling a point an outlier. Some idea of the scatter to be expected can be gathered from the data presented in [7] and [9. In particular, figure 8 of [9] shows the $\mathrm{d} U / \mathrm{d} N$ vs $G_{\max }$ behaviour for a fixed $\mathrm{d} a / \mathrm{d} N$, comparable to figure 6 in the present paper. Comparing the scatter presented in [9, the data points in figure 6 labelled as outliers for the RT, and 40 and $60{ }^{\circ} \mathrm{C}$ tests might still fall within the scatter band that is to be expected. The data for the $-20{ }^{\circ} \mathrm{C}$ test seems to fall well outside the expected scatter band around the trend line. Furthermore the $-20^{\circ} \mathrm{C}$ data is also separated from the other data if one looks at the $\mathrm{d} a / \mathrm{d} N$ vs $G_{\max }$ data (figure 1 ).

However, looking at the complete $G^{*}$ vs $G_{\max }$ data (figure 7) the four experiments identified as outliers are distinctly separated from the bulk of the data, whereas in [9. Fig. 10] all the $G^{*}$ vs $G_{\max }$ data is clustered around a single trend line. Together with the observed fractographic differences, this would 


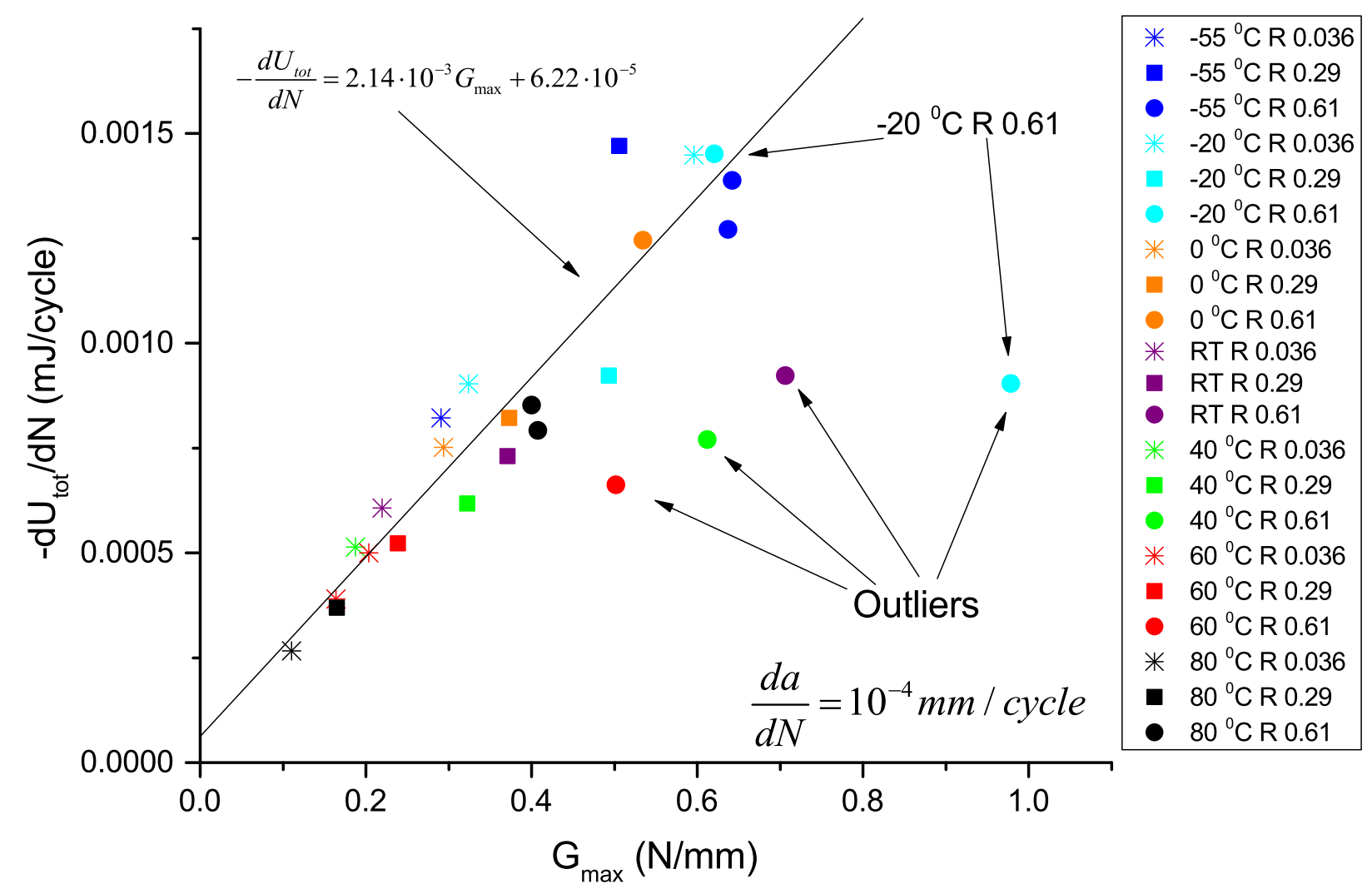

Figure 6: Energy dissipation as a function of $G_{\max }$ for a fixed value of $\mathrm{d} a / \mathrm{d} N=10^{-4} \mathrm{~mm} /$ cycle. Each point corrsponds to a single test. A linear fit through the data is also shown. The indicated points were discarded as outliers when determining the fit.

support identifying these tests as outliers.

Based on figure 7 one can then make the a number of observations.

The bulk of the data is clustered around a single trend-line, with no clear ordering corresponding to temperature. In other words, for the bulk of the data, the relationship between crack growth resistance $\left(G^{*}\right)$ and maximum load $\left(G_{\max }\right)$ does not seem to be affected by temperature.

The four tests identified as outliers are distinctly separate from the main data in figure 7 , with no clear temperature-based ordering, at least between the RT, $40{ }^{\circ} \mathrm{C}$ and $60{ }^{\circ} \mathrm{C}$ data. The fractography implies that for these tests, different fracture mechanisms were active. Figure 7 implies that, unlike temperature, this change of fracture mechanisms does affect the relationship between resistance and maximum load.

Although the relationship between resistance and maximum load is not sensitive to temperature, the same can not be said of the relationship between dissipated energy and applied cyclic work. This can be seen in figure 10. This figure shows the amount of energy dissipation, $\mathrm{d} U / \mathrm{d} N$, as a function of the applied cyclic work, $U_{c y c}$, at a fixed value of $G^{*}$. Since $G^{*}$, the amount of energy dissipation per unit of crack growth, is fixed in this representation, $\mathrm{d} U / \mathrm{d} N$ directly correlates to a certain amount of crack growth. Since the amount of energy dissipated by crack growth must equal the amount of energy available for crack growth, $\mathrm{d} U / \mathrm{d} N$ can be interpreted as representative of the amount of energy available for crack growth. In previous work a power law correlation was found between $\mathrm{d} U / \mathrm{d} N$ and $U_{c y c}$ for a fixed $G^{*}$ value [7, 9] at room temperature.

Figure 10 shows that the relationship between $\mathrm{d} U / \mathrm{d} N$ and $U_{c y c}$ is affected by temperature. In the range of 0 to $40{ }^{\circ} \mathrm{C}$ the behaviour seems to be similar, with most data points falling along the power-law fit through the room temperature data. This matches what has been previously reported [7, 9] and shows that 


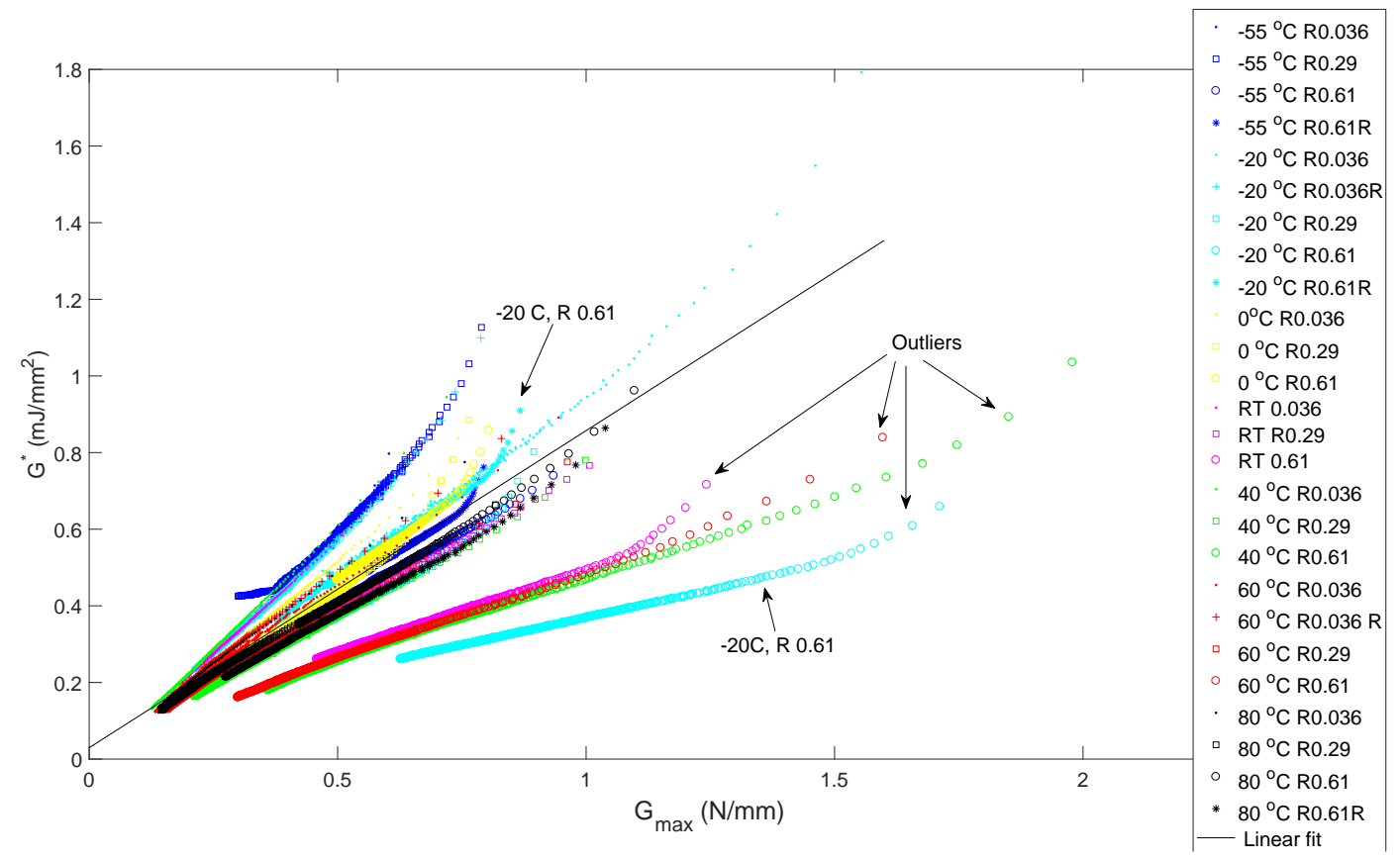

Figure 7: $G^{*}$ as a function of $G_{\max }$. Four tests show a different behaviour compared to the bulk of the data. These correspond to the four outliers marked in figure 6. A linear fit through the data is also shown $\left(R^{2}=0.8914\right)$. This fit excludes the four tests marked as outliers.

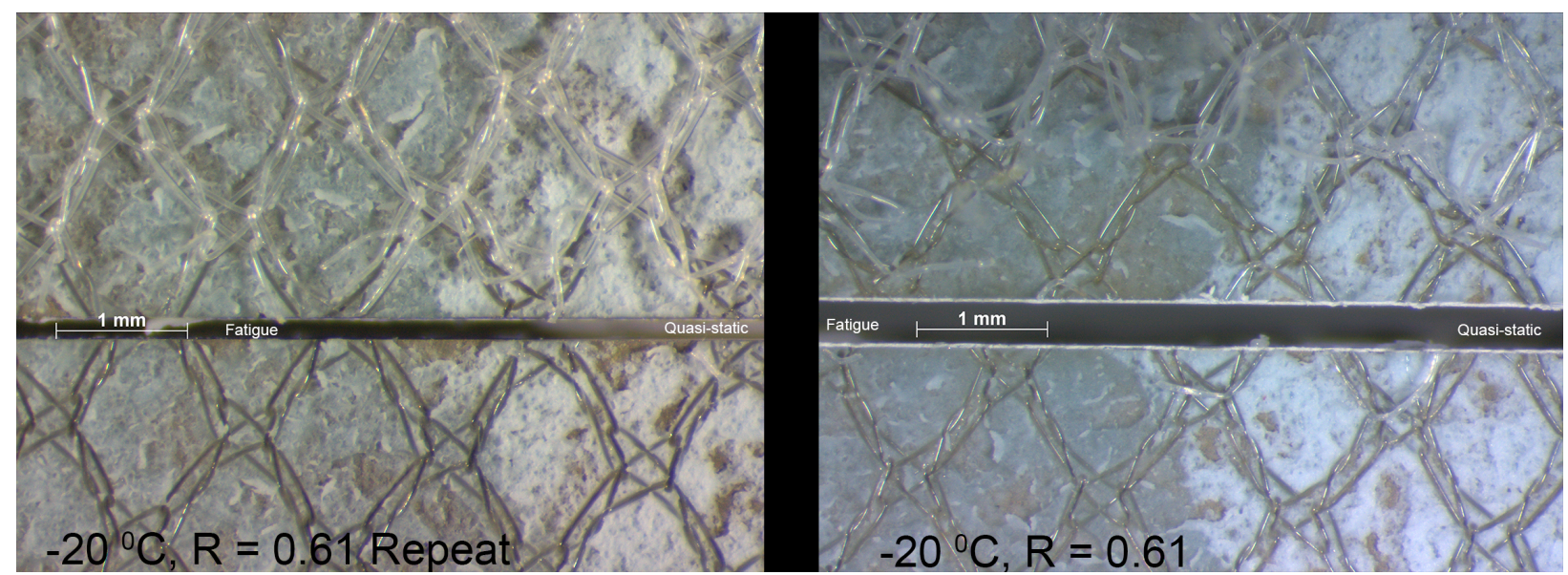

Figure 8: Image of the fracture surfaces of the two tests conducted at $-20{ }^{\circ} \mathrm{C}$ and $R=0.61$. The left panel shows the repeat test, and the right panel shows the first test. The first test (right panel) is one of the outliers identified in figures 6 and 7 . The left panel corresponds to a test whose behaviour matched that of the bulk of the experiments. The direction of crack growth was from left to right. The images show the boundary between the end of the fatigue test (left), so low crack growth rate, and the quasi-static loading (right) used to generate a new pre-crack, or break open the specimen. Both the top and bottom fracture surfaces are shown, separated by a small gap.

the amount of energy available for crack growth is related to the range of the applied load cycle.

However, at temperatures above the 0 to $40{ }^{\circ} \mathrm{C}$ range the energy dissipation for a given cyclic work value was higher. At -20 and $-55^{\circ} \mathrm{C}$ the energy dissipation for a given cyclic work was lower. Apart from that, at -20 and $-55{ }^{\circ} \mathrm{C}$ there is a less strong correlation between $\mathrm{d} U / \mathrm{d} N$ and $U_{c y c}$. A power-law fit for these temperature values also has a much higher slope than the fit through the room temperature data. The 


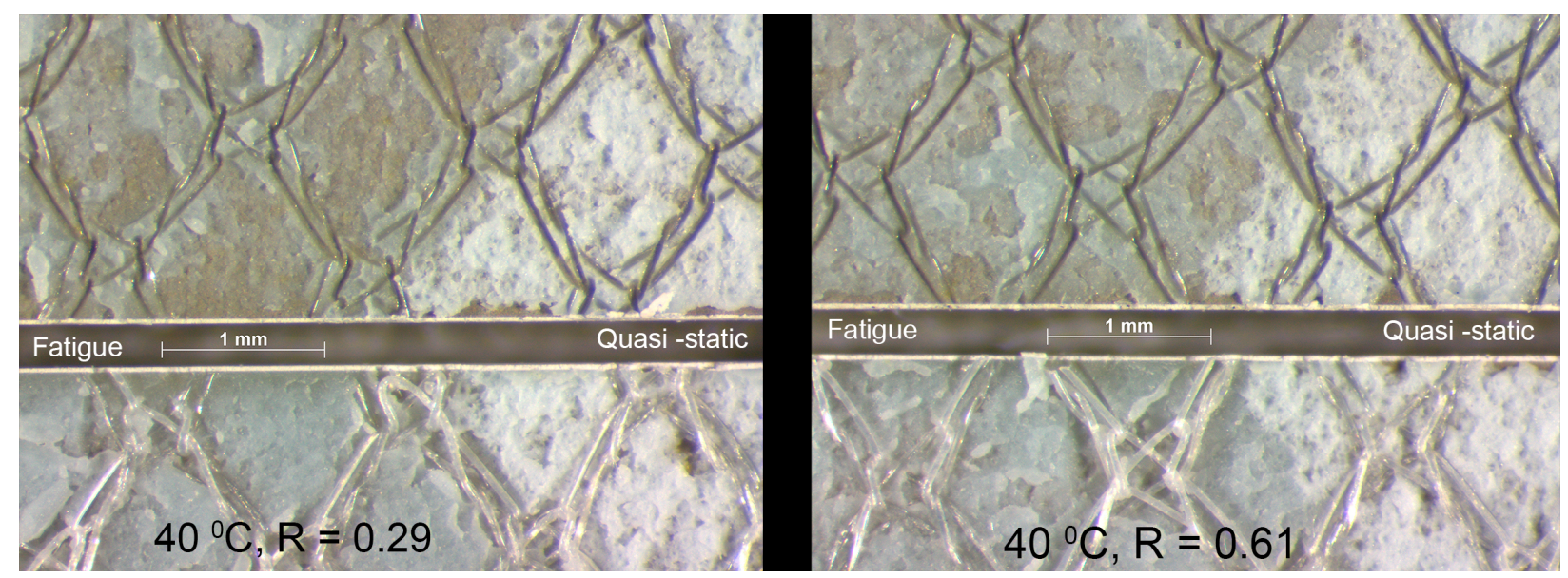

Figure 9: Image of the fracture surfaces of the tests conducted at $40{ }^{\circ} \mathrm{C}$ and $R=0.29$ (left panel) and $R=0.61$ (right panel). The test at $R=0.61$ is one of the outliers identified in figures 6 and 7 The test at $R=0.29$ had behaviour that matched that of the bulk of the experiments. The direction of crack growth was from left to right. The images show the boundary between the end of the fatigue test (left), so low crack growth rate, and the quasi-static loading (right) used to generate a new pre-crack, or break open the specimen. Both the top and bottom fracture surfaces are shown, separated by a small gap. Note the large patches free of adhesive residue on the $R=0.29$ top fracture surface (left panel).

exponent for the low temperature data is 12.72 , compared to 2.589 for the room temperature data.

A comparison of the fracture surfaces (compare figures 8 and 9 and see also [20) shows that at the low temperatures $\left(-55\right.$ and $-20{ }^{\circ} \mathrm{C}$ ) the fracture surfaces have both a different colour and a different texture than at the higher temperatures $\left(0\right.$ to $\left.40{ }^{\circ} \mathrm{C}\right)$. At lower temperatures there are more light coloured 'ridges' visible than at high temperatures.

Additionally at the highest temperatures $\left(60\right.$ and $\left.80^{\circ} \mathrm{C}\right)$ the failure appears to be largely adhesive, while at the low temperatures $\left(-55\right.$ and $\left.-20{ }^{\circ} \mathrm{C}\right)$ the failure seems to be largely cohesive. This can be inferred from the presence of adhesive residue on both fracture surfaces (for cohesive failure) or on only one surface (adhesive failure) [20].

Thus it seems likely that the change in $\mathrm{d} U / \mathrm{d} N$ vs $U_{c y c}$ behaviour is linked to the changes in failure mechanisms from cohesive to adhesive failure. Consequently, the main temperature effect seems to be that the temperature determines which failure mechanisms are active. Large temperature effects are seen when the failure mechanism changes $\left(60\right.$ and $80{ }^{\circ} \mathrm{C}$ vs -55 and $-20{ }^{\circ} \mathrm{C}$ ), whereas if the failure mechanism doesn't change (the 0 to $40{ }^{\circ} \mathrm{C}$ range) the effect of temperature remains limited.

The most likely cause for the change of mechanisms is a change of material properties due to the change of temperature. Unfortunately there is not much information available in the literature regarding the effect of temperature on the material properties of FM94. The manufacturer only provides information for the related epoxy adhesive FM73 [22]. Some data has also been published in [23, 24], but again this is for FM73. Qualitatively one may expect the same behaviour to occur in FM94, i.e. reduction of stiffness and yield strength for increasing temperature.

In the force-displacement data from the quasi-static loading performed prior to the fatigue tests, no effect of temperature is visible, and the behaviour remains linear up to the point of crack initiation / propagation. This is most likely because the stiffness of the specimens is dominated by the stiffness of the aluminium arms, which has a negligible sensitivity to temperature over the range of temperatures used in this experiment. Nevertheless, as the crack growth occurs within the epoxy layer, it seems reasonable that changes of the epoxy material properties will affect the crack growth, even if they don't affect the overall specimen stiffness.

How to relate any changes of the epoxy material properties to the fracture surface features seen during these experiments, will have to be a topic for future research. 


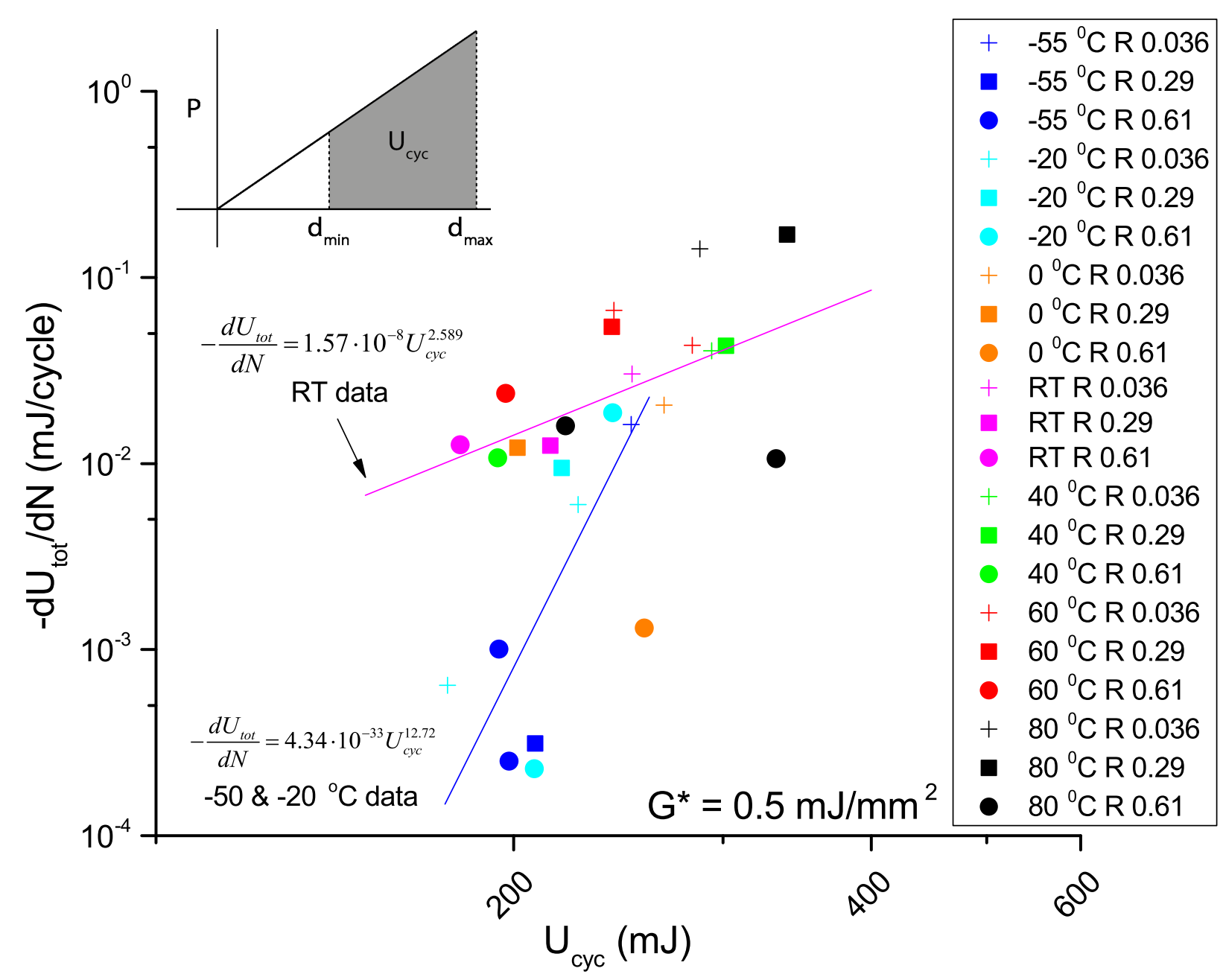

Figure 10: Energy dissipation as a function of applied cyclic work $U_{c y c}$ for a fixed value of $G^{*}=0.5 \mathrm{~mJ} / \mathrm{mm}^{2}$. Each point corresponds to a different test. Two power-law fits are show, one through the room temperature data, and one through the combined -50 and $-20{ }^{\circ} \mathrm{C}$ data.

\section{Conclusions}

Fatigue crack growth experiments were conducted on epoxy adhesive bonds at temperatures ranging from -55 to $80^{\circ} \mathrm{C}$. The effect of temperature was investigated in terms of crack growth rate for a given $G_{\max }$ and energy dissipation value. The effect of temperature on the relationship between resistance to crack growth $\left(G^{*}\right)$ and maximum load $\left(G_{\max }\right)$ was also investigated, as was the temperature effect on the relationship between energy available for crack growth $(\mathrm{d} U / \mathrm{d} N)$ and applied cyclic work $\left(U_{c y c}\right)$.

For a given $G_{\max }$ value, the crack growth rate is higher at higher temperature. Similarly, for a given value of $\mathrm{d} U / \mathrm{d} N$ the crack growth rate will also be higher for higher temperature.

The relationship between crack resistance $\left(G^{*}\right)$ and maximum load $\left(G_{\max }\right)$ seems to be largely insensitive to temperature, as shown by the linear trends in figures 6 and 7 . Four tests showed anomalous behaviour, which was linked to differences on the fracture surface.

The relationship between available energy $(\mathrm{d} U / \mathrm{d} N)$ and cyclic work $\left(U_{c y c}\right)$ was not affected by the temperature in the range of 0 to $40{ }^{\circ} \mathrm{C}$. However, at -55 and -20 , as well as at 60 and $80{ }^{\circ} \mathrm{C}$ the behaviour was different. At low temperature $\mathrm{d} U / \mathrm{d} N$ for a given $U_{c y c}$ was lower than for the range of 0 to $40{ }^{\circ} \mathrm{C}$, and $\mathrm{d} U / \mathrm{d} N$ was more sensitive to changes in $U_{c y c}$. At 60 and $80^{\circ} \mathrm{C}, \mathrm{d} U / \mathrm{d} N$ for a given $U_{c y c}$ was higher than for 
the 0 to $40{ }^{\circ} \mathrm{C}$ range. Again these differences in behaviour were linked to differences in the fracture surfaces, pointing to differences in which failure mechanisms were active.

In summary then it can be concluded that the main effect of temperature is to determine which failure mechanisms are active. If the mechanism doesn't change then temperature has a limited effect. However if different failure mechanisms are (de)activated, then the amount of energy available for crack growth and/or the resistance to crack growth for a given applied load cycle may change.

Furthermore, although the relationship between resistance and maximum load can be affected by changes of fracture mechanism, temperature mainly seems to affect the relationship between available energy and load range (cyclic work).

Presumably these changes of failure modes are linked to the effect of temperature on the material properties, but there was insufficient information available to investigate this further at present.

The final conclusion of this work is that the effect of temperature on fatigue crack growth should be understood primarily as a process that changes which failure mechanisms are activated. This process thereby affects how much energy is available for crack growth in a given cycle. How much energy is required per unit of crack growth is related to the maximum load, and this relationship is not affected by temperature.

\section{Acknowledgements}

J.A. Pascoe gratefully acknowledges the support from the Netherlands Organisation for Scientific Research (NWO) in the form of a Mosaic grant with project number: 017.009.005

\section{References}

[1] J. A. Pascoe, R. C. Alderliesten, R. Benedictus, Methods for the prediction of fatigue delamination growth in composites and adhesive bonds - a critical review, Eng Fract Mech 112-113 (2013) 72-96.

[2] A. Russell, A damage tolerance assessment of bonded repairs to CF-18 composite components part I adhesive properties, Tech. Rep. Technical Memorandum 88-25, Defence Research Establishment Pacific (1988).

[3] I. A. Ashcroft, D. J. Hughes, S. J. Shaw, M. A. Wahab, A. Crocombe, Effect of temperature on the quasi-static strength and fatigue resistance of bonded composite double lap joints, J Adhes 75 (1) (2001) 61-88.

[4] I. A. Ashcroft, S. J. Shaw, Mode I fracture of epoxy bonded composite joints 2. Fatigue loading, Int J Adhes Adhes 22 (2) (2002) 151-167.

[5] N. V. Datla, M. Papini, J. Ulicny, B. Carlson, J. K. Spelt, The effects of test temperature and humidity on the mixed-mode fatigue behavior of a toughened adhesive aluminum joint, Eng Fract Mech 78 (6) (2011) 1125-1139.

[6] J. A. Pascoe, Delamination of bonded repairs - a damage tolerance approach, Delft University of Technology, MSc thesis (2012).

[7] J. A. Pascoe, Characterising fatigue crack growth in adhesive bonds, Ph.D. thesis, Delft University of Technology, available via http://repository.tudelft.nl/islandora/object/uuid\%3Aebbf552a-ce98-4ab6-b9cc-0b939e12ba8b? collection=research (2016).

[8] J. A. Pascoe, R. C. Alderliesten, R. Benedictus, Characterising resistance to fatigue crack growth in adhesive bonds by measuring release of strain energy, Procedia Structural Integrity 2 (ECF 21) (2016) 80-87.

[9] J. Pascoe, R. Alderliesten, R. Benedictus, On the physical interpretation of the r-ratio effect and the lefm parameters used

for fatigue crack growth in adhesive bonds International Journal of Fatigue 97 (2017) 162 - 176. doi:http://dx.doi. org $/ 10.1016 / \mathrm{j}$. ijfatigue.2016.12.033

320 URL http://www.sciencedirect.com/science/article/pii/S0142112316304406

[10] W. Chan, A. Wang, Free-edge delamination characteristics in S2/CE9000 glass/epoxy laminates under static and fatigue loads, in: P. A. Lagace (Ed.), Composite Materials: Fatigue and Fracture, Second Volume, ASTM STP 1012, American Society for Testing and Materials, Philadelphia, 1989, pp. 270-295.

[11] A. Sjögren, L. E. Asp, Effects of temperature on delamination growth in a carbon/epoxy composite under fatigue loading, Int J Fatigue $24(2-4)(2002)$ 179-184.

[12] Y. Shindo, A. Inamoto, F. Narita, K. Horiguchi, Mode I fatigue delamination growth in GFRP woven laminates at low temperatures, Eng Fract Mech 73 (14) (2006) 2080-2090.

[13] Y. Shindo, T. Takeda, F. Narita, N. Saito, S. Watanabe, K. Sanada, Delamination growth mechanisms in woven glass fiber reinforced polymer composites under mode II fatigue loading at cryogenic temperatures, Compos Sci Technol 69 (11-12) (2009) 1904-1911.

[14] Y. Shindo, M. Miura, T. Takeda, N. Saito, F. Narita, Cryogenic delamination growth in woven glass/epoxy composite laminates under mixed-mode I/II fatigue loading, Compos Sci Technol 71 (5) (2011) 647-652.

[15] P. Coronado, A. Argüelles, J. Viña, V. Mollón, I. Viña, Influence of temperature on a carbon-fibre epoxy composite subjected to static and fatigue loading under mode I delamination, Int J Solids Struct 49 (21) (2012) 2934-2940. 
[16] G. Charalambous, G. Allegri, S. R. Hallett, Temperature effects on mixed mode I/II delamination under quasi-static and fatigue loading of a carbon/epoxy composite, Composites Part A 77 (2015) 75-86.

[17] D. A. Burianek, S. M. Spearing, Delamination growth from face sheet seams in cross-ply titanium/graphite hybrid laminates, Compos Sci Technol 61 (2) (2001) 261-269.

[18] C. D. Rans, R. C. Alderliesten, R. Benedictus, Predicting the influence of temperature on fatigue crack propagation in fibre metal laminates, Eng Fract Mech 78 (10) (2011) 2193-2201.

[19] ASTM Standard D 5528/ D 5528-01, Standard test method for mode I interlaminar fracture toughness of unidirectional fiber-reinforced polymer matrix composites, ASTM International, West Conshohocken, PA, USA (2007).

[20] M. Usman, Effect of temperature on fatigue crack growth rate in adhesive bonds, Ph.D. thesis, Delft University of Technology, Delft University of Technology, MSc thesis, available via/http://repository.tudelft.nl/islandora/object/ 345 uuid\%3A3ecee314-309b-4254-ab0f-34be7da90d9d? collect ion=education (2016).

[21] M. Usman, J. Pascoe, R. Alderliesten, Fatigue crack growth in FM94 epoxy adhesive bonds at different temperatures, available via: http://doi.org/10.4121/uuid:fa8bec1e-c07d-4db9-8c1a-6380bd4cba7f (2016).

[22] FM 73 adhesive film technical data sheet, Cytec Industries (2011).

[23] P. Chalkley, J. van den Berg, On obtaining design allowables for adhesives used in the bonded-composite repair of aircraft, Tech. Rep. DSTO-TR-0608, Defence Science and Technology Organisation (19987).

[24] P. Chakley, A. Baker, Adhesives Characterisation and Data Base, Vol. 1, Elsevier, Oxford, 2002, pp. 87-102. 